\title{
Greener Lubricant Formulation: Rapeseed Oil Based Eco- Friendly Lube Oil Additives
}

\author{
Sujan Paul, Dibakar Roy, Pranab Ghosh* \\ Natural Product and Polymer Chemistry Laboratory, Department of Chemistry, University of North Bengal, \\ Darjeeling, India
}

*Corresponding Author: Pranab Ghosh, Natural Product and Polymer Chemistry Laboratory, Department of Chemistry, University of North Bengal, Darjeeling, India

\begin{abstract}
Growing environmental issues over the use of mineral oil based lubricants in automobile sectors have led to an increased attention towards the use of greener environmentally benign bio-lubricants. Working in this direction, the present report describes the synthesis of homopolymer of rapeseed oil and its copolymer with styrene. Characterization of the polymer was carried out by spectral (FT-IR, NMR), GPC and thermo gravimetric analysis. Biocompatibility and multifunctional performances [viscosity index improver, pour point depressant and antiwear] in lube oil compared to conventional additives was investigated using standard ASTM methods. Biodegradability was determined by disc diffusion and soil burial degradation method.
\end{abstract}

Keywords: Rapeseed oil, styrene, viscosity index improver, pour point depressant, antiwear, biodegradability.

\section{INTRODUCTION}

The base oil or the lubricating oils is usually of petroleum origin It is a complex mixture of paraffinic, aromatic and naphthenic hydrocarbons and the main function of it is to lubricate the engine components. The addition of additives to lubricating oil is very essential for smooth functioning of modern engines. Lubricants i.e. the suitable formulated product of lube oil and additives are generally liquids or semiliquids and are used for the longevity and better performances of automotive engines. The key functions of a lubricant are to keep moving parts apart, reduce friction, protect against wear, transfer heat, prevent rust and corrosion, as antioxidant, as detergents/dispersants etc.

Although, the petroleum based lubricants exhibit satisfactory performance but they are not environmental benign due to their eco-toxicity and non-biodegradability. Strict regulations are, therefore, currently being imposed in a number of countries on lube oil-based lubricants together with their non-biodegradable toxic wastes materials (Betton et al., 2010). This increasing environmental awareness has provided researchers with the impetus to search for some new, environmentally benign, multifunctional additives. In this hunt, easily available vegetable oils have been considered as a potential candidate.

Moreover, they show excellent antiwear properties (Shanta et al., 2011), enhanced extreme pressure (EP) additive performance, exhibited high viscosity index (Ghosh et al., 2018) and low volatility (Sharma et al., 2009). There are lots of research papers where chemically modified vegetable oils have been used as additive for base oil or base stocks in the formulation of bio-lubricant (Karmakar et al., 2015).

Rapeseed oil (RO) is interesting for its richness in mono-unsaturated fatty acids, and for its low content in saturated fatty acids in comparison to other edible oils. Rapeseed oil is also frequently used in blends of vegetable oils (sunflower, soybean, corn, etc.) to improve the fatty acid profile of the vegetable oils. It has tremendous application in the field of nutritional and health claims. Apart from its above utilities, its unique composition and proven thermal stability over the other edible vegetable oils, points towards the additive properties of its suitably prepared polymers.

However research articles regarding such an application of RO as green multifunctional additive for lubricant are not yet reported.

Therefore, in this work we have synthesized homopolymer of RO (HRO) and copolymer of it with styrene in different percentage ratios to get thermally stable, cost effective as well as eco-friendly 
multifunctional lubricant additives. Performance evaluation of the prepared polymeric additives was carried out as viscosity index improver, pour point depressant and antiwear according to respective ASTM method.

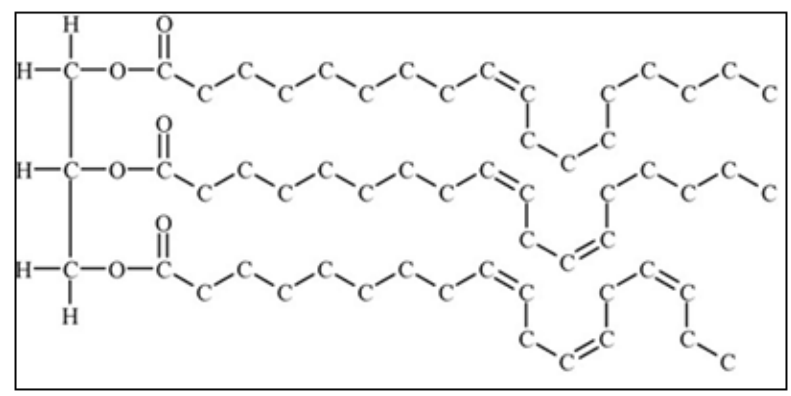

Molecular structure of rapeseed oil

\section{EXPERIMENTAL SECTION}

\subsection{Materials}

Rapeseed oil (about 90\% unsaturation) was collected from a local grocer's shop. Toluene (GC 99.5\%) was obtained from Merck Specialties Pvt. Ltd., (India). Benzoyl peroxide (LOBA chemie, India) was used after recrystallisation from chloroform- methanol mixture. Styrene (GC 99.8\%, Thomas Baker Chemicals Pvt. Ltd., India) and the mineral base oil SN150 was collected from IOCL, Dhakuria, West Bengal, India. The physical properties of the rapeseed oil and base oil are shown in table 1. Fungal specimens were collected from the sister Department, Department of Microbiology, North Bengal University, West Bengal, India for testing the biodegradability of the polymers.

Table1. Properties of Rapeseed oil and Base oil

\begin{tabular}{|c|c|c|c|}
\hline \multicolumn{2}{|c|}{ Rapeseed oil } & \multicolumn{2}{c|}{ Base oil } \\
\hline Properties & Values & Properties & Values \\
\hline Saponification index $(\mathrm{mg} / \mathrm{g})$ & $167-74$ & Density at $313 \mathrm{~K}, \mathrm{~kg} \cdot \mathrm{m}^{-3}$ & $20.31 \times 10$ \\
\hline Iodine index $(\mathrm{mg} / \mathrm{g})$ & $97-100$ & Viscosity at $313 \mathrm{~K}$ & $3.25 \times 10$ \\
\hline Refractive index at $50^{\circ} \mathrm{C}$ & 1.462 & Viscosity at $373 \mathrm{~K}$ & 85 \\
\hline Density $(\mathrm{g} / \mathrm{ml})$ & 0.916 & Viscosity index & -6 \\
\hline Saturated fatty acid $(\%)$ & 7.36 & Pour point $\left({ }^{\circ} \mathrm{C}\right)$ & -8 \\
\hline Mono unsaturated fatty acid $(\%)$ & 63.27 & Cloud point $\left({ }^{\circ} \mathrm{C}\right)$ & - \\
\hline Polyunsaturated fatty acid $(\%)$ & 28.14 & - & - \\
\hline Oleic acid $(\mathrm{g})$ & 61.744 & - & - \\
\hline Linoleic acid $\omega-6(\mathrm{~g})$ & 19.005 & - & - \\
\hline$\alpha$-Linoleic acid $\omega-3(\mathrm{~g})$ & 9.137 & - & \\
\hline
\end{tabular}

\subsection{Synthesis of the Polymers}

The copolymers were prepared by taking the monomers, $\mathrm{RO}$ and styrene at different ratios (table 2) in presence of BZP initiator by free radical polymerization method using toluene as solvent. The polymerization was accomplished in a three necked round bottom flask fitted with a magnetic stirrer, thermometer, condenser and an inlet for the introduction of nitrogen. In the flask, definite amount of rapeseed oil and styrene was heated to $80{ }^{\circ} \mathrm{C}$ and maintained for 20 minutes. Initiator BZP $(0.5 \% \mathrm{w} / \mathrm{w}$, with respect to the total monomer) was then added and refluxed for 6 hour. The detail procedure is mentioned in our previous publication (Ghosh et al., 2018).

Table2. Percentage composition and TGA values of the prepared polymers

\begin{tabular}{|c|c|c|c|c|}
\hline \multirow{2}{*}{$\begin{array}{c}\text { Polymer } \\
\text { Code }\end{array}$} & \% Composition of monomers(w/w) in the feed & \multicolumn{2}{c|}{ TGA values } \\
\cline { 2 - 5 } & RO & Sty & $160 / 320$ & $28 / 78$ \\
\hline P-1 & 100 & 0 & $210 / 355$ & $24 / 85$ \\
\hline P-2 & 98 & 2 & $266 / 382$ & $17 / 80$ \\
\hline P-3 & 96 & 4 & $268 / 382$ & $19 / 81$ \\
\hline P-4 & 94 & 6 & $268 / 384$ & $18 / 79$ \\
\hline P-5 & 92 & 8 & Decom. Temp. & PWL \\
\hline RO = Rapeseed oil; Sty = Styrene; Decom. Temp.=Decomposition temperature; PWL= Percentage Weight \\
\multicolumn{3}{|c}{} \\
\hline
\end{tabular}




\subsection{Spectroscopic Measurements}

NMR spectra were recorded on Bruker Avance $300 \mathrm{MHz}$ FT-NMR spectrometer using a $5 \mathrm{~mm}$ BBO probe. $\mathrm{CDCl}_{3}$ and tetramethylsilane (TMS) was used as solvent and as reference material respectively. IR spectra were recorded on a Shimadzu FT-IR 8300 spectrometer using $0.1 \mathrm{~mm} \mathrm{KBr}$ cells at room temperature within the wave number range of 400 to $4000 \mathrm{~cm}^{-1}$.

\subsection{Molecular Weight Determination}

The number average molecular weight $\left(\mathrm{M}_{\mathrm{n}}\right)$ and weight average molecular weight $\left(\mathrm{M}_{\mathrm{w}}\right)$ were measured by GPC method (Water 2414, polystyrene calibration) in HPLC grade THF at room temperature at a flow rate of $1 \mathrm{~mL} / \mathrm{min}$.

\subsection{Thermo Gravimetric Analysis (TGA)}

TGA data was measured on Shimadzu TGA-50 system, at a heating rate of $10^{\circ} \mathrm{C} / \mathrm{min}$.

\section{Performance Evaluation}

\subsection{Evaluation of Viscosity Index}

The change of viscosity of the lubricant with increasing temperature is expressed in terms of a parameter called Viscosity index (VI). It was calculated according to ASTM D 2270-10. The kinematic viscosities which are essential to calculate the VI values of the lubricant composition were determined at $40{ }^{\circ} \mathrm{C}$ and $100{ }^{\circ} \mathrm{C}$. The effect of additive concentration on VI was investigated by using different concentrations ranging from $1 \%-5 \%(\mathrm{w} / \mathrm{w})$.

\subsection{Evaluation of Pour Point}

Pour point of the additive blended lube oil was determined according to the ASTM D 97-09 method using the cloud and pour point tester model WIL-471 (India).

\subsection{Evaluation of Anti Wear Performance}

The antiwear performance of the lubricant compositions in terms of wear scar diameter (WSD) was determined by Four-ball wear test apparatus (FBWT) following the ASTM D 4172-94 method. In this experiment $392 \mathrm{~N}(40 \mathrm{Kg})$ load at $75^{\circ} \mathrm{C}$ for $60 \mathrm{~min}$ was applied to measure the wear scar diameter. The diameter and rotating speed of the ball were $12.7 \mathrm{~mm}$ and $1200 \mathrm{rpm}$ respectively.

\subsection{Biodegradability Test [dks]}

Several tests have been devised for measuring the biodegradability of vegetable oil based additives, as they have an inherent biodegradability compared to the synthetic additives. In the present investigation it was tested by (a) the disc diffusion method against fungal pathogens (Ghosh et al., 2010) and (b) the soil burial degradation test.

\subsection{Disc Diffusion (DD) Method}

In this method, biodegradation of the prepared additives were tested against four different fungal pathogens, viz. Colletotrichum camelliae (CC), Fusarium equiseti (FE), Alternaria alternate (AA) and Colletotrichum gloeosporioides (CG) in a bacteriological incubator (Sigma Scientific Instruments Pvt. Ltd., India). Culture media for the fungal strains were prepared by mixing potato extract, dextrose, and agar powder in a 10:1:1 proportion by weight. $1.0 \mathrm{~g}$ of each of the polymeric additives were placed in Petri dishes with $2 \mathrm{~g}$ of the culture media and incubated at $310 \mathrm{~K}$ for 30 days with the different fungal pathogens. The fungal growth was confirmed by a change of colour from yellow to blackish. After 30 days, the additive samples were recovered from the fungal media and washed with chloroform, purified and dried. Finally, the weight loss for each of the samples was calculated.

\subsection{Soil Burial Degradation Test (SBD Test)}

In this test method the microorganisms attacks the surface of the polymer film (Liu et al., 2010). $1.0 \mathrm{~g}$ of each of the polymeric additive was taken to produce the polymer films. The films so obtained were then buried in soil (containing the microorganisms) in a bacteriological incubator. The soil was placed in a tray, the relative humidity was maintained to 50-60\% with the help of a humidity chamber and the temperature was set at $303 \mathrm{~K}$. The soil used in this study was taken from the campus of the North Bengal University (West Bengal, India) with $\mathrm{pH} 7.3$ and moisture content of $25 \%$. The buried polymer films 
were recovered at regular intervals of 15 days up to a period of 3 months with a different film for each time period. Recovered films after the biodegradation test were washed with chloroform, filtered with Whatman grade 41 filtration paper and dried in a vacuum oven at $323 \mathrm{~K}$. They were then purified by precipitation of their hexane solution by methanol and then dried in a vacuum oven at $323 \mathrm{~K}$ to constant weight. The test was carried as per ISO 846:1997 (Chandure et al., 2007; Ghosh et al., 2014). The extent of degradation of the additives in the tests was determined by measuring the percent weight loss (PWL) of the samples. The PWL was determined by the equation,

$\mathrm{PWL}=\left[\left(M_{0}-M_{1}\right) / M_{0}\right] \times 100$

Where, $\mathrm{M}_{0}$ is the initial mass and $\mathrm{M}_{1}$ is the remaining mass after the test and subsequent drying until constant weight. The degradation of the polymers was also established by observing the shift in the IR frequency of the ester carbonyls after the biodegradability test.

\section{RESUltS AND DisCuSSION}

\subsection{Spectroscopic Data Analysis}

The spectroscopic data of all the prepared polymers were analyzed to confirm the predicted structure of the additives. In case of copolymer, the characteristic IR absorption peak at $1743 \mathrm{~cm}^{-1}$ was for the ester carbonyl group of the rapeseed oil part along with other peaks in the range $2857 \mathrm{~cm}^{-1}$ to $2931 \mathrm{~cm}^{-1}$. The peaks at $810 \mathrm{~cm}^{-1}, 756 \mathrm{~cm}^{-1}, 724 \mathrm{~cm}^{-1}$ and $695 \mathrm{~cm}^{-1}$ were assigned to the phenyl group of styrene. A peak at around $3000 \mathrm{~cm}^{-1}$ was due to stretching of C-H bond of aromatic ring (figure 1).

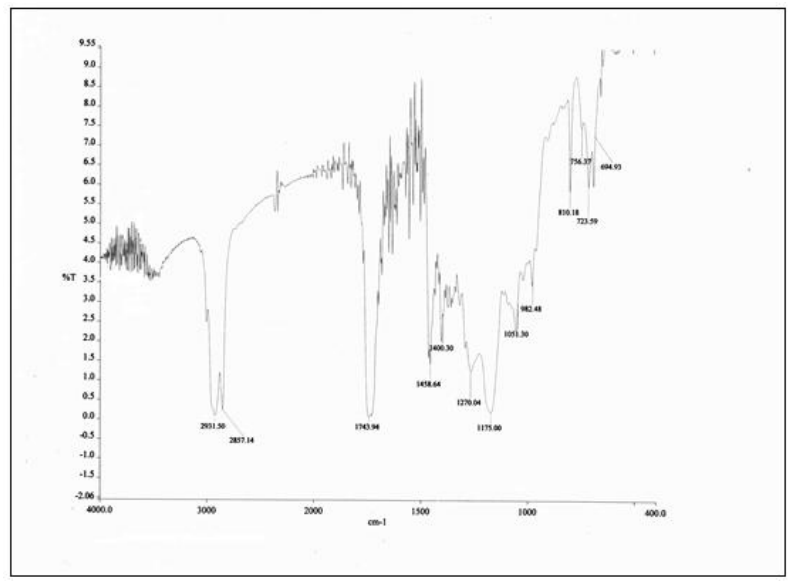

Figure1. A representative FT-IR spectrum of the rapeseed oil-styrene copolymer

In the ${ }^{1} \mathrm{H}$ NMR, the methyl protons appear in the range of $0.88-0.90 \mathrm{ppm}$, the methylene protons in the range of $1.28-1.63 \mathrm{ppm}$ and the methine protons appeared in the range of $2.04-2.30 \mathrm{ppm}$ for the alkyl chains. A peak at $4.08 \mathrm{ppm}$ indicates the protons of $-\mathrm{OCH}_{2}$ group. The peaks in the range of 4.10 - $4.15 \mathrm{ppm}$ indicate the protons of $-\mathrm{COOCH}_{2}$ group of rapeseed oil. A broad peak in the range of 6.80 - $7.64 \mathrm{ppm}$ indicates the protons of aromatic ring of styrene (figure 2).

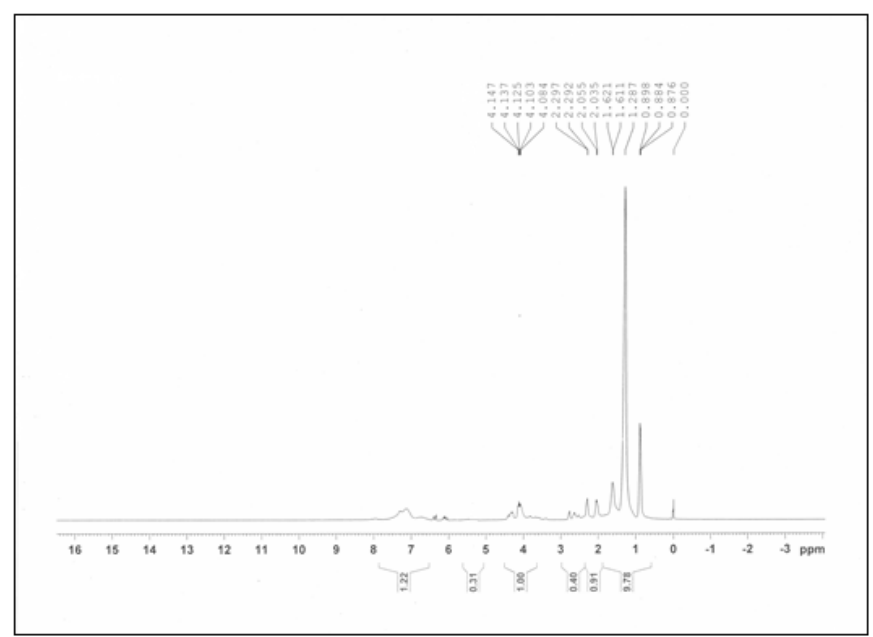

Figure2. A representative ${ }^{l} H$ NMR spectra of rapeseed oil -styrene copolymer 
In the ${ }^{13} \mathrm{C}$ NMR of the copolymer, the peaks in the range of $14.14-41.03 \mathrm{ppm}$ were due to carbons of all $\mathrm{CH}_{3}$ and $\mathrm{CH}_{2}$ groups. The peaks at $58.13 \mathrm{ppm}$ indicate the methine carbons of $-\mathrm{CH}-$ of $-\mathrm{COCH}-$ group. The peaks in the range of $60-62.08 \mathrm{ppm}$ represent the carbons of $-\mathrm{OCH}_{2}$ groups. The $-\mathrm{CH}_{2}$ carbons of $-\mathrm{OCOCH}_{2}-$ group of rapeseed oil showed peaks in the range of $64.61-68.99 \mathrm{ppm}$. The aromatic carbons appear in the range of $127.93-130.88 \mathrm{ppm}$. The peaks in the range of $165.65-$ $173.00 \mathrm{ppm}$ confirms the carbons of ester carbonyl groups (figure 3).

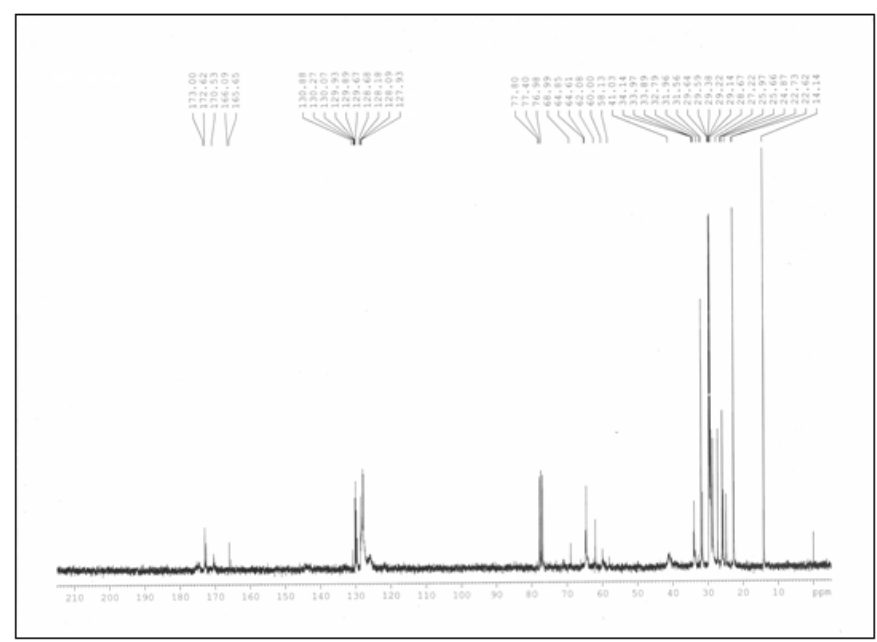

Figure3. A representative ${ }^{13} \mathrm{C}$ NMR spectra of rapeseed oil -styrene copolymer

In case of homopolymer of rapeseed oil, the IR absorption band at $1741 \mathrm{~cm}^{-1}$ (figure 4) showed the presence of ester carbonyl group. In the ${ }^{1} \mathrm{H}$ NMR spectra of homopolymer of rapeseed oil (figure 5), the peaks in the range of 4.12- $4.33 \mathrm{ppm}$ indicate the protons of $-\mathrm{COOCH}_{2}$ group of rapeseed oil, the methyl protons appear in the range of $0.86-0.90 \mathrm{ppm}$, the methylene protons in the range of $1.26-1.62$ ppm and the methine protons appeared in the range of $2.29-2.34 \mathrm{ppm}$ for the alkyl chains (figure 5). In the ${ }^{13} \mathrm{C}$ NMR spectra of homopolymer of rapeseed oil, the ester carbonyl group appears at 173.98 ppm, the carbons of $-\mathrm{OOCH}_{2}$ group of appears at 62.07-68.91 ppm (figure 6).

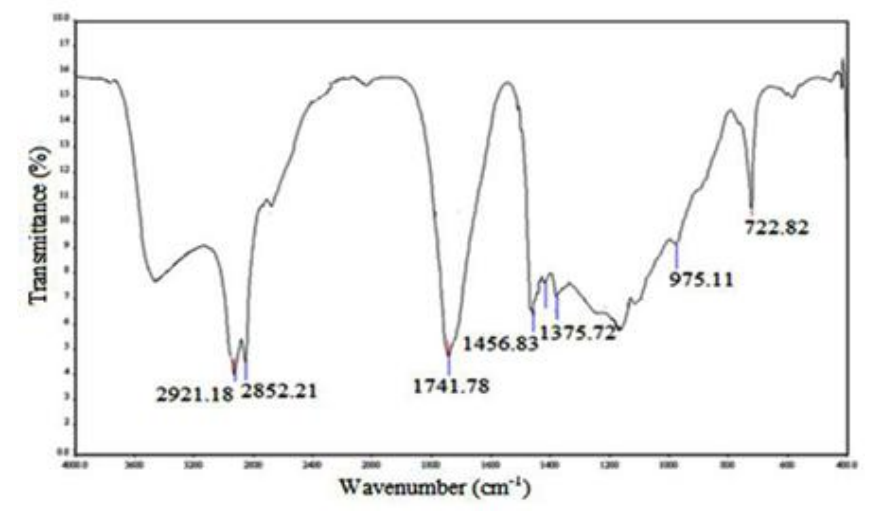

Figure4. FT-IR spectra of the homopolymer of rapeseed oil

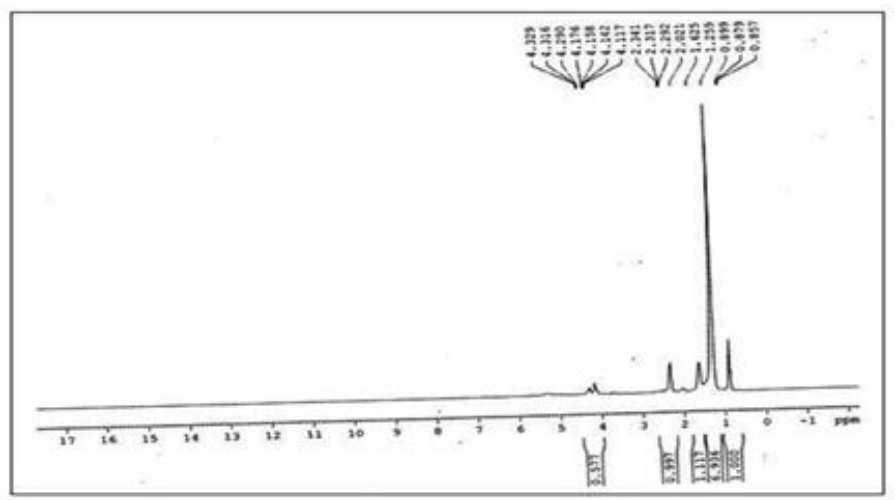

Figure5. ${ }^{1} \mathrm{H}$ - NMR spectra of homopolymer of rapeseed oil 


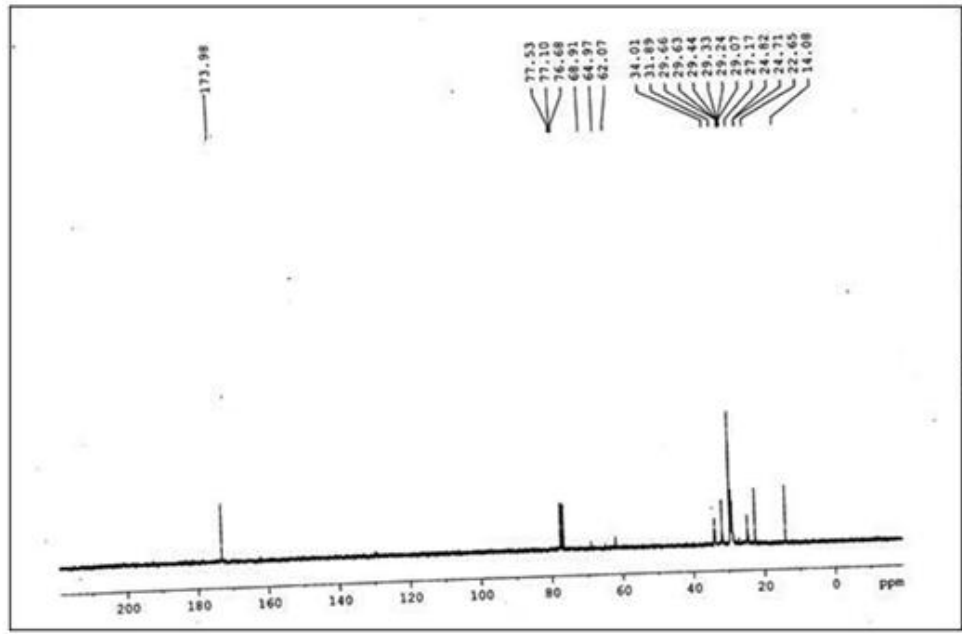

Figure6. ${ }^{13} C$ - NMR spectra of homopolymer of rapeseed oil

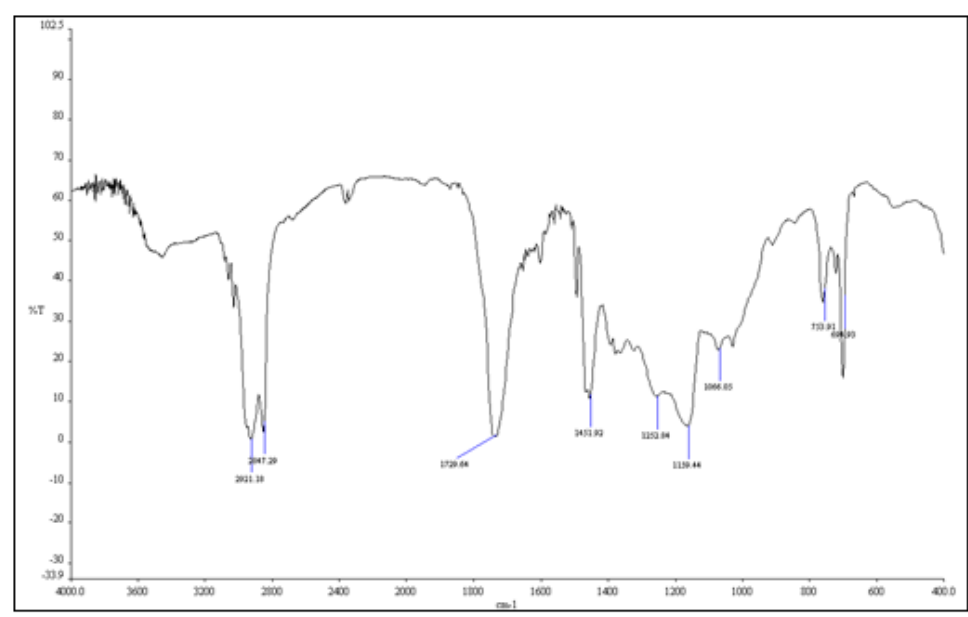

Figure7. A representative FT-IR spectrum of the copolymer after biodegradability test

\subsection{Molecular Weight Data Analysis}

The experimental values of number average molecular weights $\left(\mathrm{M}_{\mathrm{n}}\right)$ and weight average molecular weights $\left(\mathrm{M}_{\mathrm{w}}\right)$ of the prepared polymers (P-1 to P-5) are given in table 3. From the experimental data, it is seen that among the five polymers, P-5 has highest molecular weight. Moreover, it is also observed that with increasing the percentage of styrene in the backbone of rapeseed oil, the molecular weight increases. Therefore, percentage of styrene has a significant role during polymerization.

Table3. Molecular weight of the prepared polymers

\begin{tabular}{|c|c|c|c|c|c|c|}
\hline \multirow{2}{*}{$\begin{array}{c}\text { Polymer } \\
\text { Code }\end{array}$} & \multicolumn{3}{|c|}{$\begin{array}{c}\text { Average molecular weight } \\
\text { (before biodegradation) }\end{array}$} & \multicolumn{3}{c|}{$\begin{array}{c}\text { Average molecular weight } \\
\text { (after biodegradation) }\end{array}$} \\
\cline { 2 - 7 } & $\mathrm{M}_{\mathrm{n}}$ & $\mathrm{M}_{\mathrm{w}}$ & PDI & $\mathrm{M}_{\mathrm{n}}$ & $\mathrm{M}_{\mathrm{w}}$ & PDI \\
\hline P-1 & 8328 & 11522 & 1.31 & 4132 & 4645 & 1.26 \\
\hline P-2 & 18657 & 26536 & 1.34 & 14211 & 21427 & 1.44 \\
\hline P-3 & 19497 & 29166 & 1.43 & 15512 & 24876 & 1.59 \\
\hline P-4 & 22671 & 33612 & 1.88 & 16536 & 29271 & 1.73 \\
\hline P-5 & 29654 & 38644 & 1.29 & 22320 & 29664 & 1.34 \\
\hline
\end{tabular}

\subsection{Analysis of TGA Data}

The TGA values of the five polymers are given in table 2. From the table, it is clear that the thermal degradation of polymer P-1 is higher than the other polymers which signify that P-1 is thermally less stable. The thermal degradation of polymers P-3, P-4 and P-5 are almost similar. In case of polymer P1, major decomposition starts at $160{ }^{\circ} \mathrm{C}$ with about $30 \%$ weight loss. For polymers P-3, P-4 and P-5, major decomposition starts approximately at $268{ }^{\circ} \mathrm{C}$ with $18 \%$ weight loss. Due to copolymerization of rapeseed oil with styrene, the thermal stability increases. Therefore, copolymerization with styrene has a significant importance to improve the thermal stability. 


\subsection{Analysis of Viscosity Index Values}

VI was calculated at different concentrations ranging from $1 \%$ to $5 \%(\mathrm{w} / \mathrm{w})$ to the base oil. The experimental values of VI are given in table 4. From the table, it is found that VI values increase with increasing the concentration of polymers in base oil. The viscosity of lubricating oil decreases with increasing temperature but expansion of polymer molecules take place with increasing temperature and due to this, the size of micelle increases. This increased in micelle size interfere the reduction of the viscosity of the lubricant (Tanveer et al., 2006). Moreover, with increasing the concentration of polymer in lubricating oil leads to an increase in the total volume of polymer micelle in lube oil and improves the VI property (Karmakar et al., 2013). It has been observed that VI value increases by incorporation of styrene in the backbone of homopolymer of rapeseed oil. This may be due to higher crosslink density of the copolymers. The copolymer P-5 has highest effect on VI increment followed by P-4, P-3, P-2 and $\mathrm{P}-1$. The higher values VI in case of P-5 containing maximum percentage of styrene in the feed, are due to greater volume of the solvated additive molecule i.e. micelle compared to others which may be associated with its higher average molecular weights and lower PDI value.

Table4. Viscosity index (VI) values of polymer blended base oil

\begin{tabular}{|c|c|c|c|c|c|c|}
\hline \multirow{2}{*}{$\begin{array}{c}\text { Polymer } \\
\text { Code }\end{array}$} & \multicolumn{6}{|c|}{ VI of polymer blended base oil at different concentrations( w/w) } \\
\cline { 2 - 7 } & $0 \%$ & $1 \%$ & $2 \%$ & $3 \%$ & $4 \%$ & $5 \%$ \\
\hline P-1 & 85 & 89 & 95.5 & 104 & 112 & 118 \\
\hline P-2 & 85 & 94 & 98 & 112 & 115 & 128 \\
\hline P-3 & 85 & 96 & 104 & 114 & 123 & 131 \\
\hline P-4 & 85 & 101 & 106 & 116 & 124 & 133 \\
\hline P-5 & 85 & 103.5 & 111 & 125 & 135 & 145 \\
\hline
\end{tabular}

\subsection{Analysis of Pour Point Values}

The pour points of the lubricants prepared by blending the polymers at different concentration levels ranging from $1 \%-5 \%(\mathrm{w} / \mathrm{w})$ are shown in table 5. All the polymers are effective as PPD and the efficiency as pour point increases with increasing the concentration of polymers up to certain limit (4\% concentration). This indicates that at this concentration, the polymer interacts with the paraffinic wax of base oil effectively and decreases the size of crystals of the paraffinic wax (El-Gamal et al., 1997). Among the prepared five polymers, P-4 showed better performance as PPD.

Table5. Pour point values of polymer blended base oil

\begin{tabular}{|c|c|c|c|c|c|c|}
\hline \multirow{2}{*}{$\begin{array}{c}\text { Polymer } \\
\text { Code }\end{array}$} & \multicolumn{5}{|c|}{ Pour point $\left({ }^{\circ}\right.$ C) of lubricant at different concentrations (w/w) } \\
\cline { 2 - 6 } & $0 \%$ & $1 \%$ & $2 \%$ & $3 \%$ & $4 \%$ & $5 \%$ \\
\hline P-1 & -6 & -9 & -12 & -12 & -15 & -16 \\
\hline P-2 & -6 & -10 & -12 & -16 & -18 & -16 \\
\hline P-3 & -6 & -10 & -12 & -16 & -20 & -18 \\
\hline P-4 & -6 & -12 & -15 & -18 & -22 & -24 \\
\hline P-5 & -6 & -10 & -15 & -18 & -18 & -22 \\
\hline
\end{tabular}

\subsection{Analysis of Anti Wear Properties}

The tribological properties of the lubricant compositions were determined by measuring WSD through FBWT apparatus applying $392 \mathrm{~N}$ load and values are given in table 6 . The anti wear performance of the lube oil is significantly improved when the polymers are blended with it and is reflected in the lower WSD values of the lubricant compositions. The copolymers showed better result compared to the homopolymer. The polymer P-5 at 5\% concentration showed highest reduction in WSD values compared to the other polymers. This indicates that the film formed by the lubricant between the two moving metal surfaces is very strong. It may be due to higher molecular weight and hence higher number of polar side chains of the ester carbonyl groups and hydroxyl groups present in rapeseed oil (Masjuki et al., 1997). The contribution of higher percentage of styrene in the polymer feed has also played a significant role in it with its aromatic ring structure.

Table6. Antiwear property in terms of wear scar diameter (WSD in $\mathrm{mm}$ ) values of different lubricant composition

\begin{tabular}{|c|c|c|c|c|c|c|}
\hline \multirow{2}{*}{$\begin{array}{c}\text { Polymer } \\
\text { Code }\end{array}$} & \multicolumn{5}{|c|}{ WSD of lubricant (in mm) at different polymer concentrations (w/w) } \\
\cline { 2 - 7 } & $0 \%$ & $1 \%$ & $2 \%$ & $3 \%$ & $4 \%$ & $5 \%$ \\
\hline P-1 & 1.116 & 1.067 & 1.044 & 1.025 & 1.007 & 0.964 \\
\hline P-2 & 1.116 & 1.065 & 1.037 & 1.023 & 1.003 & 0.957 \\
\hline
\end{tabular}




\begin{tabular}{|l|l|l|l|l|l|l|}
\hline P-3 & 1.116 & 1.060 & 1.028 & 1.018 & 0.992 & 0.955 \\
\hline P-4 & 1.116 & 1.052 & 1.022 & 1.002 & 0.958 & 0.931 \\
\hline P-5 & 1.116 & 1.031 & 1.013 & 0.992 & 0.943 & 0.911 \\
\hline
\end{tabular}

\subsection{Analysis of Biodegradability Test}

Biodegradability test results (table 7) with the homo (P-1) and copolymers (P-2 to P-5) showed significant biodegradability against the fungal pathogens, Calletotricheme camellia andAlterneria alternata, though the result is, as expected, better for the homopolymer of rapseed oil. A close observation of the test results showed considerable biodegradation for all the samples. The analysis of the SBD tests indicated that the degradation of the additives studied increased continuously with the increasing number of days. Further, both the homo and copolymer of showed significant weight losses against the fungal pathogens, especially against Alternaria alternate (AA), in the DD test. Moreover, as expected for zero styrene content and owing to the presence of the natural monomer unit, the HRO (P-1) showed the highest biodegradability among all the additives in both of the tests. The FT- IR peaks of the polymer P-1 showed shift in the peak positions and considerable decrease in peak height and intensity after the DD test. The shift and the decrease in the IR peak intensities of the polymers before and after the biodegradation tests together with the PWL of the polymers confirmed the biodegradable nature of the prepared polymers.

Table7. Result of biodegradability test by the disc diffusion method and soil burial degradation.

\begin{tabular}{|c|c|c|c|c|c|c|}
\hline \multirow{2}{*}{ Sample } & \multicolumn{7}{|c|}{$\begin{array}{c}\text { Weight loss in disc diffusion method(g) } \\
\text { [Pathogens used] }\end{array}$} & $\begin{array}{c}\text { Weight loss in soil burial } \\
\text { degradation } \\
(\mathrm{g})\end{array}$ \\
\cline { 2 - 7 } & {$[\mathrm{CC}]$} & {$[\mathrm{FE}]$} & {$[\mathrm{AA}]$} & {$[\mathrm{CG}]$} & {$[\mathrm{CE}]$} & 0.47 \\
\hline P-1 & 0.45 & 0 & 0.62 & 0 & 0 & 0.35 \\
\hline P-2 & 0.38 & 0 & 0.54 & 0 & 0 & 0.30 \\
\hline P-3 & 0.30 & 0 & 0.48 & 0 & 0 & 0.25 \\
\hline P-4 & 0.26 & 0 & 0.39 & 0 & 0 & 0.19 \\
\hline P-5 & 0.22 & 0 & 0.35 & 0 & 0 & 0.19 \\
\hline CC = Calletotricheme camellia; FE = Fussarium equisitae; AA = Alterneria alternata; CG = Colletrichum \\
gleosproides; CE= Curvularia eragrostidies. \\
\hline
\end{tabular}

\section{CONCLUSION}

From the above study it was found that the copolymer of rapeseed oil with styrene showed excellent multifunctional performance for base oil. As a viscosity index improver, pour point depressant and antiwear additive, the copolymers are found more effective than the homopolymer. In addition, the presence of rapseed oil in the additive composition introduces excellent biodegradability too, in the additive. Average molecular weight and thermal stability of the copolymers increases with the increase in the percentage of styrene. Therefore, the above study is definitely a potential approach to formulate a greener lubricant composition with excellent multifunctional additive properties for lube oil.

\section{ACKNOWLEDGEMENT}

The authors thank to UGC, New Delhi for financial support. Special thanks to IOCL, India for providing the base oil.

\section{REFERENCES}

[1] Betton CI (2010) Lubricants and Their Environmental Impact. In: Chemistry and Technology of Lubricants, Eds. Mortier RM, Fox MF, Orszulik ST, Springer, The Netherlands, pp. 435-457.

[2] Chandure AS, Umare SS (2007) Synthesis, Characterization and Biodegradation Study of Low Molecular Weight Polyesters. Int J Polym Mater 56: 339-353.

[3] El-Gamal, I.M., Atta, A. M., and Al-Sabbagh, A. M. (1997). Polymeric structures as cold flow improvers for waxy residual fuel oil. Fuel 76:1471-1478.

[4] Ghosh, P., Hoque, M., and Karmakar. G. (2018). Castor oil as potential multifunctional additive in the formulation of eco-friendly lubricant. Polym. Bull. 75:501-514

[5] Ghosh P, Das T, Nandi D, Karmakar G, Mandal A (2010) Synthesis and characterization of biodegradable polymer: Used as a pour point depressant for lubricating oil. Int J Polym Mater 59: 1008-1017

[6] Karmakar, G., and Ghosh, P. (2013). Green additives for lubricating oil. ACS Sustainable Chem. Eng. 1:1364-1370. 
[7] Karmakar, G., and Ghosh, P. (2015). Soybean oil as a biocompatible multifunctional additive for lubricating oil. ACS Sustainable Chem. Eng. 3: 19-25.

[8] Ghosh P, Karmakar G (2014) Evaluation of sunflower oil as a multifunctional lubricating oil additive. Int J Ind Chem 5: 7

[9] Liu M, Huang Z, Yang Y (2010) Analysis of biodegradability of three biodegradable mulching films. $J$ Polym Environ 18: 148-154.

[10] Masjuki, H. H., Maleque, M. A. (1997). Investigation of the anti-wear characteristics of palm oil methyl ester using a four-ball tribometer test. Wear 206: $179-186$.

[11] Shanta, S. M., Molina, G. J., and Soloiu, V. (2011). Tribological effects of mineral-oil lubricant contamination with biofuels: A pin-on-disk tribometry and wear study. Adv. Tribol. doi:10.1155/2011/820795.

[12] Sharma, B. K., Adhvaryu, A., and Erhan, S. Z. (2009). Friction and wear behavior of thioether hydroxyl vegetable oil. Wear 42:353-358.

[13] Tanveer, S., Sharma, U. C., and Prasad, R. (2006). Rheology of multigrade engine oils. Indian J. Chem. Technol. 13:180-184.

Citation: Sujan Paul, Dibakar Roy, Pranab Ghosh, "Greener Lubricant Formulation: Rapeseed Oil Based Eco-Friendly Lube Oil Additives", International Journal of Petroleum and Petrochemical Engineering, 6(3), pp. 29-37. DOI: https:// doi.org/10.20431/2454-7980.0603004

Copyright: (C) 2020 Authors, this is an open-access article distributed under the terms of the Creative Commons Attribution License, which permits unrestricted use, distribution, and reproduction in any medium, provided the original author and source are credited. 